Du C., L.C. Dias, F. Freire, Robust multi-criteria weighting in comparative LCA and S-LCA: A case study of sugarcane production in Brazil, Journal of Cleaner Production, Vol. 218, May 2019, 708-717.

https://doi.org/10.1016/j.jclepro.2019.02.035

\title{
Robust multi-criteria weighting in comparative LCA and S-LCA: a case study of sugarcane production in Brazil
}

\begin{abstract}
This article presents a novel multi-criteria decision analysis (MCDA) model for performing robust indicator weighting in Life Cycle Assessment (LCA) and Social Life Cycle Assessment (S-LCA). This model integrates stochastic weights analysis with preference information that utilizes the value judgements of decision makers, benefitting from the diversity of interests and familiarities of decision makers regarding each indicator. The model considers all decision makers on an equal basis but does not assume they have the same importance. The MCDA model was applied to support the evaluation of the overall environmental and social impacts of manual and mechanical sugarcane harvesting in Brazil based on LCA and S-LCA. Brazilian experts were surveyed on the weights of relevant environmental and social indicators. The novel MCDA approach explores all the possible convex combinations of the weights provided by the surveyed group. The results of the MCDA model show that mechanical harvesting compared to manual harvesting had lower environmental life cycle impacts at the end-point level and better social impacts for all these convex combinations. Decision-making based on environmental impacts at the mid-point level is less clear: manual harvesting is more likely ( $67 \%$ of the convex combinations of the weights) to be considered better than mechanical harvesting; but the advantage of mechanical harvesting over manual harvesting can be greater than the reverse (almost twice as large). This article recommends presenting both mid-point and end-point LCIA results for a thoroughly informed decision-making. The MCDA model developed in this article can also be used to support weighting in future comparative LCA or S-
\end{abstract} LCA studies.

Keywords: multi-criteria decision analysis, life cycle assessment, social life cycle assessment, weighting, sugarcane 


\section{Introduction}

Brazil, the world's largest sugarcane producer, has seen a rapid expansion of its sugarcane planted area over the past decade, with an annual growth rate of $6.5 \%$ (UNICA, 2017). The center-south states of Brazil were responsible for $93 \%$ of total production in the 2016/2017 harvest, producing 652 million tons of sugarcane and feeding the production of 38.7 million tons of sugar and 27.3 billion liters of ethanol (UNICA, 2017). The operations of Brazilian sugarcane production have also evolved, with increased use of mechanical harvesting. This change is largely driven by government incentives; for instance, the Green Protocol, a voluntary agreement between the Government of São Paulo and the Sugarcane Agro-industrial Sector, was established to phase out pre-harvest burning, resulting in an increase in mechanical harvesting (UNICA, 2010). The adoption of mechanical harvesting is expected to reduce environmental impacts and public health risks, but concerns regarding its social impacts have been raised, namely, job loss among sugarcane cutters (Arbex et al., 2007; Cançado et al., 2006; Duarte et al., 2013; Galdos et al., 2013; Viana and Perez, 2013).

Life cycle assessment (LCA) is a widely applied method for assessing the environmental impacts associated with the life cycle of a product (or service), from cradle to grave. According to ISO standards (ISO, 2006a), LCA is organized into four phases: i) goal and scope definition, where the system boundary and functional unit are defined; ii) life cycle inventory analysis (LCI), where the input/output data of the product system are quantified; iii) life cycle impact assessment (LCIA), which associates LCI data with specific environmental impact categories and category indicators; and iv) interpretation, where results are summarized and discussed as a basis for conclusions. LCIA methods can be organized as midpoint (also known as problem-oriented) or endpoint methods (also known as damage-oriented), according to the level of the cause-effect chain. Adopting a life cycle perspective avoids the shifting of burdens among life cycle phases, impact categories, regions or generations (Guinée et al., 2011). Derived from LCA, social life cycle assessment (SLCA) is an emerging method to evaluate social impacts of supply chains (Du et al., 2014). Compared to other social impact assessment tools, SLCA focuses on a product (or service) level and considers the entire life cycle and a broader range of stakeholders (UNEP/SETAC, 2009).

Several LCA and SLCA studies have assessed the environmental and the social impacts of the mechanization of Brazil's sugarcane sector (Chagas et al., 2016; Du et al., 2017; Galdos et al., 2013; Macedo et al., 2008; Souza et al., 2016). None of these studies considers both environmental and social impacts in the same study. Moreover, their results are presented following characterization based on a set of environmental or social indicators, with no further analysis with regard to supporting decision-making. A notable exception in this panorama is the 
recent work of Cardoso et al (2018), which uses a computer-based simulator to assess environmental, social, and other indicators to demonstrate how multi-criteria decision analysis could inform decision-making.

LCA or S-LCA results provide information on the environmental and social impacts of alternative scenarios, but analyzing trade-offs among multiple indicators to determine which alternative is preferable can be difficult for decision makers. Normalization, weighting and aggregation are optional steps in LCIA, where characterized results are converted to comparable measures and then aggregated into a single score based on the weights allocated to each indicator (Guinee, 2002). Weighting is subjective and implies a value judgement which may influence the results of an LCA. As stated in ISO14044 (ISO 2006b), "weighting shall not be used in LCA studies intended to be used in comparative assertions intended to be disclosed to the public". However, weighting is commonly used in studies due to its practicality for comparing the impacts of different products or scenarios, supporting decision-making and results communication (Pizzol et al., 2017).

Giving equal weights to all indicators is a common workaround in LCA (Huppes and van Oers, 2011; Pizzol et al., 2017); however, this arbitrary choice ignores the preferences and knowledge of decision makers or experts. Multi-criteria decision analysis (MCDA) has been considered a promising tool to aid weighting in LCIA and/or interpretation of LCA or S-LCA results. MCDA methods using outranking approaches (Domingues et al., 2015; Prado-Lopez et al., 2014; Rogers and Seager, 2009) or additive aggregation approaches (Dias et al., 2016; Miettinen and Hamalainen, 1997; Myllyviita et al., 2012) have been applied to LCA and S-LCA studies to rank, select or categorize products based on their environmental and/or social impacts. Dias et al. (2016) adopted stochastic weights in an additive aggregation model with partial preference information. This approach allows identifying robust conclusions, but it does not utilize the preferences and knowledge of decision makers and experts. Other studies based on additive aggregation often elicit weights through a survey, with the final weight of an indicator usually being calculated by averaging the weights given to that indicator by all respondents (Doderer and Kleynhans, 2014; Lipuscek et al., 2010; Narayanan et al., 2007; Pastare et al., 2014). This approach ignores the different levels of interest in and familiarity with the topic of each indicator among decision makers. According to a recent survey conducted among LCA practitioners (Pizzol et al., 2017), further development is needed to improve uncertainty and robustness of weighting in life cycle studies. Ideally, the knowledge of decision makers or experts would be considered, but weights allocated to decision makers in group decisionmaking are often unknown (Sarabando et al. 2017). A robust aggregation approach of group decision-making based on LCA and/or S-LCA results is lacking. 
This article describes a novel approach to support decision-making based on comparative LCA and S-LCA results using an additive MCDA group decision-making model (Dyer and Sarin, 1979; Keeney et al., 1975). The approach developed in this article is distinguished from previous studies by its adoption of stochastic weights accounting for the value choices of a group of decision makers. Instead of assigning equal weights to all decision makers, the stochastic weights analysis explores all possible combinations, making no distinctions among the weights assigned their opinions. The advantage of this approach is to generate robust results that aggregate the preference information of all the decision makers. This approach was applied to support the comparison between manual and mechanical sugarcane harvesting in Brazil in terms of environmental and social impacts. The results of this study shed light on the advantages of including both mid-point and end-point categories in an LCA.

\section{Methods}

2.1. Life cycle assessment and social life cycle assessment of manual vs. mechanical harvesting of sugarcane

We compared life cycle environmental and social impacts of manual and mechanical harvesting of sugarcane by applying LCA and SLCA, respectively, described hereafter (Du et al. 2017, Du et al. 2018). Based on the results of these studies, manual harvesting has shown to have higher impacts on three out of eight mid-point impact categories assessed, namely Climate change, Photochemical oxidant formation and Particulate matter formation. At the end-point level, manual harvesting shows worse performance on Human health and Ecosystem diversity, but better performance on Resource availability. Regarding social impacts, mechanical harvesting is expected to have lower impacts on all social themes except for Local employment and Access to material resources.

\subsubsection{Life cycle assessment}

An attributional LCA of sugarcane in Brazil was performed considering the functional unit of one tonne of sugarcane at the distillery, encompassing cultivation, harvesting and transportation. Two product systems were compared, one using manual harvesting (including pre-harvest burning) and the other using mechanical harvesting (without pre-harvest burning). The life cycle inventory was based on average conditions of the center-south region of Brazil and extracted from the database of Brazilian Bioethanol Science and Technology Laboratory (CTBE) (Bonomi et al., 2016). Production and field emissions of raw materials (i.e., organic and inorganic fertilizers, agrochemicals, diesel), transport of raw materials and final products (i.e. transporting harvested sugarcane to the distillery), and production of capital goods including harvesters, tractors and agricultural machineries were included in the system 
boundary. Details of the applied assumptions and emission factors can be found in Du et al. (2017).

The LCIA method ReCiPe (Goedkoop et al., 2013) was adopted to characterize environmental impacts at the mid-point and end-point. The mid-point categories of Climate change, Ozone depletion, Terrestrial acidification, Freshwater eutrophication, Human toxicity, Photochemical oxidant formation, Particulate matter formation and Fossil depletion were assessed. These mid-point categories were selected following previous LCA studies (e.g., Cavalett et al., 2013; Luo et al., 2019; Seabra et al., 2011) and considering the importance of environmental issues surrounding sugarcane production and agricultural practices in Brazil; for instance, water depletion was not included because the water needed for sugarcane crops in Brazil is mostly supplied by rainfall. LCA results were also calculated for the end-point categories of Human health, Ecosystem and Resources.

\subsubsection{Social life cycle assessment}

A screening S-LCA was conducted to identify the social hotspots of sugarcane in Brazil and to compare the social impacts of manual and mechanical harvesting. A novel approach integrating the generic Social Hotspots Database (SHDB) and content analysis was developed. The social impacts of the sugarcane life cycle were firstly modelled in SHDB; in this step, three country-sector pairs were included in the system boundary after applying the cut-off criterion of only considering country-sectors contributing more than $1.5 \%$ of total worker hours, namely sugarcane, commerce and business services sectors of Brazil. The sugarcane sector dominated the social impacts in all indicators due to its large share in overall worker hours (85\%). SHDB mostly includes data at the country level; as a result, it has a limited ability to distinguish between the social impacts of different operations in the same sector, such as manual and mechanical harvesting of sugarcane. Content analysis was subsequently applied to systematically analyze relevant publications regarding the social impacts of sugarcane production in Brazil. In total, 38 publications published in English between 2000 and 2016 were included in the final analysis. The social impacts of manual and mechanical sugarcane harvesting were compared according to eight social themes based on the qualitative data extracted from the literature, including health and safety, local employment, fair salary, access to material resources, delocalization and migration, public commitment to sustainability issues, safe and healthy living conditions and equal opportunity and discrimination. These social themes were selected because they are the most relevant social issues surrounding the sugarcane sector in Brazil; moreover, social impacts on these issues differ between manual and mechanical harvesting. Please refer to Du et al. (2018) for details regarding the methods and materials of this screening S-LCA. 


\subsection{Normalization of $L C A$ and $S$ - $L C A$ results}

Normalization is an optional step in LCA applied after the characterization of environmental impacts as mid-point and/or end-point indicators. Because characterized LCIA results are expressed in various units for various indicators, normalization can convert the results into commensurable measures or reveal the magnitude of impacts (Dias et al., 2016; Myllyvitta et al., 2014). Normalization can be conducted externally or internally. External normalization relates the characterized scores of a product system to a reference value, e.g., indicator results for a reference area or a reference scenario (Domingues et al., 2015; Myllyvitta et al., 2014). In internal normalization, characterized values are not related to external references but values of a baseline scenario such as a given alternative product system. Two extreme values, i.e. minimum and maximum values are often considered in internal normalization. When applying MCDA approaches, internal normalization is more commonly used, for instance in multi-attribute value theory (MAVT) (Keeney and Raiffa, 1993) and Analytic Hierarchy Process (AHP) (Saaty, 2008). This article deploys internal normalization following Equation 1 in order to match the way that indicator weights are elicited (comparing the magnitude of the difference between manual and mechanical systems). Because only two alternatives are compared in this article, the normalized values of two alternatives on all the indicators are either 0 (best impact level) or 1 (worst impact level).

$I_{j}\left(a_{i}\right)=\frac{I_{j}^{o}\left(a_{i}\right)-I_{j, \min }^{o}}{I_{j, \text { max }}^{o}-I_{j, \text { min }}^{o}}$

$I_{j}^{o}\left(a_{i}\right)$ : characterized value of alternative ai on indicator $\mathrm{j}$, in the original units (before normalization);

$I_{j, m i n}^{o}=\min _{i}\left\{I_{j}^{o}\left(a_{i}\right)\right\}:$ the best performance on indicator $\mathrm{j}$;

$I_{j, \text { max }}^{o}=\max _{i}\left\{I_{j}^{o}\left(a_{i}\right)\right\}:$ the worst performance on indicator $\mathrm{j}$.

It should be noted that if an impact indicator is to be maximized (the more, the better) keeping value 0 assigned to the best impact level and value 1 to the worst impact level, then the difference $I_{j}^{o}\left(a_{i}\right)-I_{j, \text { min }}^{o}$ should be replaced by the difference $I_{j, \text { max }}^{o}-I_{j}^{o}\left(a_{i}\right)$ in the numerator of Equation (1). Although internal normalization is the most relevant approach to this study, it is worth mentioning that adding a new alternative may result in changes to the relative positions of original alternatives (Dias and Domingues, 2014; Norris, 2001). If a new alternative were added where any of its impacts were higher than the previous maximum or lower than the previous minimum, then the survey would have to be repeated considering the new (wider) difference between the best and worst impact levels.

For social impacts, the assessment of this study is based on qualitative data. For comparative purposes, the qualitative results of each indicator are quantified by a binary scoring rule: the best performance is assigned 0 and the worst performance is assigned 1 . 


\subsection{Multi-criteria decision analysis approach: an additive model with stochastic weights}

A novel multi-criteria decision analysis approach based on additive aggregation has been developed and applied to compare the overall environmental and social impacts of manual and mechanical sugarcane harvesting in Brazil. The overall impact of an alternative (a product system) $a_{i}$, denoted $I\left(a_{i}, w\right)$, is calculated by Equation 2, which is a weighted sum of its impact on indicator $j$ (i.e. $\left.I_{j}\left(a_{i}\right)\right)$ considering the corresponding weight $w_{j}$. All the weights are nonnegative and the sum of all weights is equal to 1 (Equation 3 ).

$I\left(a_{i}, w\right)=\sum_{j=1}^{n} w_{j} I_{j}\left(a_{i}\right)=w_{1} I_{1}\left(a_{i}\right)+\cdots+w_{j} I_{j}\left(a_{i}\right)+\cdots+w_{n} I_{n}\left(a_{i}\right)$

$w_{1}, w_{2} \ldots . w_{n} \geq 0$ and $\sum_{j=1}^{n} w_{j}=1$

$w$ : a vector of weights for all the indicators, $\left(w_{1}, w_{2}, \ldots ., w_{n}\right)$;

$a_{i}$ : an alternative; in this case, the sugarcane product system with manual or mechanical harvesting;

$w_{j}$ : the weight of indicator $\mathbf{j}$; in this case, mid-point impact category, end-point damage category or social theme, respectively;

$I_{j}\left(a_{i}\right)$ : the normalized value of alternative $a_{i}$ on indicator $j$;

$n$ : the number of indicators used in the assessment.

The weight of indicator $j, w_{j}$, is calculated by Eq. 4 and 5, in which $\mu_{p}$ represents the weight assigned to the preference of decision maker $p$ when calculating the weight of the indicators. Decision maker weights $\mu_{1}, \ldots, \mu_{m}$ are computed based on Monte Carlo simulation using the software @Risk 7.5, considering a uniform distribution over the unit simplex, according to the process described in Butler et al. (1997). All weights assigned to decision makers are non-negative and the sum of all weights equals 1.

$w_{j}=\sum_{p=1}^{m} \mu_{p} w_{j p}=\mu_{1} w_{j 1}+\mu_{2} w_{j 2}+\cdots+\mu_{m} w_{j m}$

$\mu_{1}, \ldots, \mu_{m} \geq 0$ and $\sum_{p=1}^{m} \mu_{p}=1$

$p$ : decision maker;

$m$ : the total number of decision makers;

$w_{j p}$ : the weight of indicator $j$ assigned by decision maker $p$;

$\mu_{p}$ : the stochastic weight assigned to decision maker $p$.

It is worth mentioning that each vector of weights assigned to decision makers, $\left(\mu_{1}, \ldots\right.$, $\left.\mu_{m}\right)$, will correspond to a vector of indicator weights $\left(w_{1}, w_{2}, \ldots, w_{n}\right)$ that is a convex combination of the indicator weights provided by the decision makers. The resulting vector of indicator weights can then be seen as a mix of the inputs provided by different decision makers. When all the individual weight vectors satisfy Equation 3, then Equation 4 and 5 guarantee that the resulting vector $\left(w_{1}, w_{2}, \ldots, w_{n}\right)$ will also satisfy Equation 3. 
In order to collect preference information from relevant decision makers, a survey was conducted to gather experts' opinions on their value choices for eight mid-point environmental indicators, three end-point environmental indicators and eight social indicators. The survey material can be found in Supplementary Material. To obtain survey responses that represent the values of informed decision makers, only experienced Brazilian LCA researchers and practitioners (over 5 years of experience in LCA) with knowledge of the sugarcane sector in Brazil were invited to answer the survey. In total, 26 surveys were sent out with 7 responses received (response rate 27\%). These responses are sufficient to illustrate the methodology proposed in this work, but do not warrant any claims that they represent the entire universe of Brazilian LCA researchers.

The survey participants were asked to give a weight (between 0 and 100) to each environmental or social indicator, considering both the context of sugarcane production in Brazil and the magnitude and significance of the impact of changing from manual to mechanical harvesting (information provided with the questionnaire). The characterized values of mid-point and end-point environmental impacts and a summary of social performances for each social indicator in regard to manual and mechanical harvesting were provided to participants. One example of survey instruction regarding mid-point environmental impacts reads: "Considering i) the context of sugarcane production in Brazil, and ii) the importance of impacts due to changing from manual to mechanical harvesting (e.g., on climate change, reducing emissions from $38 \mathrm{kgCO}_{2}$ eq $\mathrm{t}$ of sugarcane to $29 \mathrm{kgCO}_{2}$ eq $/ \mathrm{t}$ of sugarcane), please assign weights (0-100 points) to the mid-point indicators below. All assigned weights should have a total sum of 100 points."

It is worth noting that $\mathrm{w}_{\mathrm{j}}$ represents the importance of the impact change on indicator $j$ comparing mechanical harvesting to manual harvesting rather than the importance of the indicator $j$ itself. On the other hand, $\mu$ p simulates the weight assigned to decision maker $p$ when setting the weights for each indicator.

\subsection{VIP Analysis}

VIP (Variable Interdependent Parameter) Analysis is based on the additive aggregation model of value functions. It does not require decision makers to indicate precise values as criteria weights, and it can be used to generate robust conclusions using every accepted combination of weights. VIP Analysis has the ability to find the most extreme values with respect to the differences between the overall results of two alternatives (Dias and Climaco 2000). The value difference between two alternatives $a_{i}$ and $a_{j}$ can be defined by Equation 6 , where $D_{\max }\left(a_{i}, a_{j}\right)$ and $D_{\min }\left(a_{i}, a_{j}\right)$ indicate the highest and lowest values of $D\left(a_{i}, a_{j}\right)$, respectively. 
In the above equation, $w \in W$ represents the set of all indicator weights corresponding to the convex combinations of weights assigned by different decision makers (Fig. 1). This figure illustrates a situation with four decision makers. The shaded area corresponds to all possible convex combinations of weights $w_{(1)}, \ldots, w_{(4)}$ provided by the decision makers. Each point in this figure corresponds to a weighted sum (using positive coefficients $\mu_{1}, \ldots, \mu_{m}$ adding up to 1) of the extreme points defining this set. As an example, the point highlighted in blue corresponds to the convex combination $0.50 w_{(1)}+0.25 w_{(2)}+0.15 w_{(3)}+0.10 w_{(4)}$.

When $D\left(a_{i}, a_{j}\right)$ is negative, it means that $a_{i}$ has lower impacts than $a_{j}$, since only negative impacts are considered in the LCA and the objective is to minimize them. Likewise, $a_{i}$ presents higher impacts than $a_{j}$ when $D\left(a_{i}, a_{j}\right)$ is positive. Applying the additive model with both stochastic weights (described in Section 2.4) and VIP Analysis can provide complementary outputs: the former can indicate the probability that one alternative is better than the other, while the latter reveals how much better or worse can one alternative can be over the other.

\subsection{Sensitivity analysis}

In order to test the robustness of the results concerning the choice of decision makers, a sensitivity analysis adopting the one-at-a-time (OAT) approach (Czitrom, 1999) is conducted. The answers of one decision maker are removed at a time, and the results are then compared to evaluate the effect of this decision maker's preferences on the overall output. This approach can effectively identify outliers, although it has been criticized for its limitation in detecting interactions between input variables (Czitrom, 1999). As the survey is conducted independently for each decision maker, this limitation is not relevant to this article.

\section{Results and discussion}

\subsection{Mid-point environmental impacts}

\subsubsection{Comparing environmental impacts on mid-point impact categories}

The characterized values of mid-point impacts of manual and mechanical harvesting are normalized by Equation 1. Characterized and normalized mid-point LCA results are presented in Table 1. Because the goal concerning environmental impacts is to minimize them, a normalized value 0 represents a better performance between the two alternatives, while 1 represents a worse performance. Mechanical harvesting is better according to the indicators Climate change, Photochemical oxidant formation and Particulate matter formation, whereas manual harvesting is better according to the indicators Fossil depletion, Ozone depletion, Terrestrial acidification, Freshwater eutrophication and Human toxicity. 


\section{Table 1}

Mid-point LCA results of manual and mechanical harvesting.

\begin{tabular}{|c|c|c|c|c|c|}
\hline \multirow[b]{2}{*}{ Impact category } & \multicolumn{3}{|c|}{ Characterized LCA results } & \multicolumn{2}{|c|}{ Normalized LCA results } \\
\hline & Unit & $\begin{array}{l}\text { Manual } \\
\text { harvesting }\end{array}$ & $\begin{array}{l}\text { Mechanical } \\
\text { harvesting }\end{array}$ & $\begin{array}{l}\text { Manual } \\
\text { harvesting }\end{array}$ & $\begin{array}{l}\text { Mechanical } \\
\text { harvesting }\end{array}$ \\
\hline Climate change & $\mathrm{kg} \mathrm{CO}_{2} \mathrm{eq}$ & 38.32 & 28.85 & 1 & 0 \\
\hline Fossil depletion & $\mathrm{kg}$ oil eq & 6.66 & 7.80 & 0 & 1 \\
\hline Ozone depletion & $\mathrm{kg} \mathrm{CFC}_{-11}$ eq & $1.47 \mathrm{E}-06$ & $1.75 \mathrm{E}-06$ & 0 & 1 \\
\hline Terrestrial acidification & $\mathrm{kg} \mathrm{SO}_{2} \mathrm{eq}$ & 1.34 & 1.57 & 0 & 1 \\
\hline Freshwater eutrophication & $\mathrm{kg} P$ eq & $1.90 \mathrm{E}-03$ & $1.99 \mathrm{E}-03$ & 0 & 1 \\
\hline Human toxicity & $\mathrm{kg} 1,4-\mathrm{DB}$ eq & 4.22 & 4.38 & 0 & 1 \\
\hline $\begin{array}{l}\text { Photochemical oxidant } \\
\text { formation }\end{array}$ & kg NMVOC & $6.83 \mathrm{E}-01$ & 8.05E-02 & 1 & 0 \\
\hline Particulate matter formation & $\mathrm{kg} \mathrm{PM}_{10}$ eq & $5.76 \mathrm{E}-01$ & $2.24 \mathrm{E}-01$ & 1 & 0 \\
\hline
\end{tabular}

\section{Table 2}

Survey results of weights of mid-point indicators.

\begin{tabular}{|c|c|c|c|c|c|c|c|}
\hline Impact category & Expert 1 & Expert 2 & Expert 3 & Expert 4 & Expert 5 & Expert 6 & Expert 7 \\
\hline Climate change & 25 & 40 & 50 & 15.1 & 23 & 25 & 15 \\
\hline Fossil depletion & 20 & 20 & 20 & 13.2 & 20 & 22.5 & 13 \\
\hline Ozone depletion & 2.5 & 10 & 5 & 9.4 & 1 & 17.5 & 8 \\
\hline Terrestrial acidification & 10 & 5 & 0 & 11.3 & 20 & 5 & 11 \\
\hline $\begin{array}{l}\text { Freshwater } \\
\text { eutrophication }\end{array}$ & 2.5 & 10 & 0 & 9.4 & 4 & 5 & 11 \\
\hline Human toxicity & 20 & 0 & 0 & 14.2 & 18 & 5 & 15 \\
\hline $\begin{array}{l}\text { Photochemical oxidant } \\
\text { formation }\end{array}$ & 5 & 10 & 5 & 13.2 & 8 & 5 & 12 \\
\hline $\begin{array}{l}\text { Particulate matter } \\
\text { formation }\end{array}$ & 15 & 5 & 20 & 14.2 & 6 & 15 & 15 \\
\hline
\end{tabular}

The survey results of weights of mid-point indicators are shown in Table 2. The values are divided by 100 in the final analysis so that all weights add up to 1 . The weight vector representing the weights assigned to decision makers for each indicator $\left(\mu_{1}, \mu_{2}, \ldots \mu_{7}\right)$ is simulated for 100,000 iterations. Since the objective is to compare manual and mechanical harvesting systems, the results of interest are the differences between the overall results of the two alternatives. As shown in Fig. 2, obtained by performing a Monte Carlo simulation, the overall impact of the manual system is more likely to be lower than the overall impact of the mechanical system. The manual system is preferred to the mechanical system in $67 \%$ of cases. Following the VIP Analysis approach, the minimum and the maximum values, -0.26 and 0.50 , respectively, indicate that, despite the manual system having a higher possibility of winning, the advantage at best of the manual system (0.26, i.e., the symmetric value of the minimum) is less 
than the advantage at best of the mechanical system (0.50) (these are exact values, which constitute a wider interval than the interval estimated by the simulation).

Based on these results, there is no clear conclusion about which system is preferable: for some weight vectors, it is the manual system, while for other weight vectors it is the mechanical system. The manual system is preferred for a fairly large majority $(67 \%)$ of the weight vectors, but the mechanical system, on the other hand, can potentially beat the manual system by a larger margin than the reverse.

\subsubsection{Sensitivity analysis}

The robustness of the previous results is assessed in terms of whether a single participant might have a large influence on the results. One expert (decision maker) is removed at a time, reducing the number of experts to 6 . Table 3 shows the results of the sensitivity analysis of mid-point indicators based on Monte Carlo simulation and VIP analysis. Regardless of which expert is removed, the manual system is more likely to be preferred to the mechanical system (all differences are negative for more than 50\% of the simulated weights). However, when removing expert 3, the result is overwhelmingly in favor of the manual system (in $99 \%$ of the cases), winning by a margin of 0.26 at best, and losing by a relatively small margin of 0.10 at worst. This is because expert 3 provides the highest weights on Climate change (50\%) and Particulate matter formation (20\%) out of all the experts, and the manual harvesting system has worse performance in these indicators. When removing expert 5, the probability of the mechanical system being preferred increases to $49.7 \%$ (nearly 50\%), and the advantage at best of the mechanical system is almost three times larger than the advantage of the manual system at best. In the cases of removing other experts (i.e. expert 1, 2, 4, 6 or 7), the probability of the manual system winning over the mechanical system ranges between $56.8 \%$ and $73.2 \%$, and the margins in the manual system's worst cases are always larger than the margins of its best cases.

\section{Table 3}

Sensitivity analysis of mid-point impacts considering the influence of a single expert.

\begin{tabular}{lcccccccr}
\hline & $\begin{array}{c}\text { Without } \\
\text { Expert1 }\end{array}$ & $\begin{array}{c}\text { Without } \\
\text { Expert2 }\end{array}$ & $\begin{array}{c}\text { Without } \\
\text { Expert3 }\end{array}$ & $\begin{array}{c}\text { Without } \\
\text { Expert4 }\end{array}$ & $\begin{array}{c}\text { Without } \\
\text { Expert5 }\end{array}$ & $\begin{array}{c}\text { Without } \\
\text { Expert6 }\end{array}$ & $\begin{array}{c}\text { Without } \\
\text { Expert7 }\end{array}$ & $\begin{array}{c}\text { Original } \\
\text { Overall }\end{array}$ \\
\hline $\begin{array}{l}\text { Minimum } \\
\text { (VIP analysis) }\end{array}$ & -0.26 & -0.26 & -0.26 & -0.26 & -0.16 & -0.26 & -0.26 & -0.26 \\
$\begin{array}{l}\text { Maximum } \\
\text { (VIP analysis) }\end{array}$ & 0.50 & 0.50 & 0.10 & 0.50 & 0.50 & 0.50 & 0.50 & 0.50 \\
Mean & -0.01 & -0.04 & -0.11 & -0.00 & 0.02 & -0.01 & -0.00 & -0.02 \\
Std Dev & 0.09 & 0.09 & 0.04 & 0.09 & 0.09 & 0.09 & 0.09 & 0.08 \\
$\begin{array}{l}\text { \% of cases with } \\
\text { I(manual) - }\end{array}$ & & & & & & & & \\
I(mechanical)<0 & 60.6 & 73.2 & 98.9 & 57.4 & 50.3 & 60.6 & 56.8 & 67 \\
\hline
\end{tabular}




\subsection{End-point environmental impacts}

\subsubsection{Comparing environmental impacts on end-point damage categories}

Table 4 presents the characterized and normalized end-point LCA results of the manual and mechanical systems, in which 0 once again indicates better indicator performance. Mechanical harvesting is better in terms of damage to Human health and to Ecosystem diversity, while manual harvesting is better in terms of damage to Resource availability.

Table 5 shows the weights of end-point indicators given by seven experts. The values are also divided by 100 in the final analysis and the weight vectors indicating decision maker weights $\left(\mu_{1}, \mu_{2}, \ldots, \mu_{7}\right)$ are simulated for 100000 iterations. Results of differences between the manual and the mechanical systems at the end-point are presented in Fig. 3. It is clear that, in regard to end-point indicators, the manual system is always less preferred than the mechanical system, with the smallest margin of 0.20 (putting all the weight in expert 3), and the largest margin of 0.80 (putting all the weight in expert 5). The manual system might have been preferred in some instances, had a decision maker assigned a weight of 50 or more to the single category where this system was better (Damage to resource availability), but this did not occur in this survey.

\section{Table 4}

End-point LCA results of manual and mechanical harvesting.

\begin{tabular}{lccccc}
\hline \multirow{2}{*}{ Damage category } & \multicolumn{3}{c}{ Characterized LCA results } & \multicolumn{2}{c}{ Normalized LCA results } \\
\cline { 2 - 6 } & Unit & $\begin{array}{l}\text { Manual } \\
\text { harvesting }\end{array}$ & $\begin{array}{l}\text { Mechanical } \\
\text { harvesting }\end{array}$ & $\begin{array}{l}\text { Manual } \\
\text { harvesting }\end{array}$ & $\begin{array}{l}\text { Mechanical } \\
\text { harvesting }\end{array}$ \\
\cline { 2 - 6 } $\begin{array}{l}\text { Damage to human } \\
\text { health }\end{array}$ & DALY & $2.06 \mathrm{E}-04$ & $1.02 \mathrm{E}-04$ & 1 & 0 \\
$\begin{array}{l}\text { Damage to } \\
\text { ecosystem diversity }\end{array}$ & Species*year & $3.11 \mathrm{E}-07$ & $2.38 \mathrm{E}-07$ & 1 & 0 \\
$\begin{array}{l}\text { Damage to resource } \\
\text { availability }\end{array}$ & $\$$ & 1.1 & 1.3 & 0 & 1 \\
\hline
\end{tabular}

\section{Table 5}

Survey results of weights of end-point damage categories.

\begin{tabular}{lccccccc}
\hline Damage category & Expert 1 & Expert 2 & Expert 3 & Expert 4 & Expert 5 & Expert 6 & Expert 7 \\
\hline $\begin{array}{l}\text { Damage to human } \\
\text { health }\end{array}$ & 30 & 30 & 40 & 35 & 50 & 40 & 40 \\
$\begin{array}{l}\text { Damage to ecosystem } \\
\text { diversity }\end{array}$ & 50 & 40 & 20 & 33 & 40 & 30 & 30 \\
$\begin{array}{l}\text { Damage to resource } \\
\text { availability }\end{array}$ & 20 & 30 & 40 & 33 & 10 & 30 & 30 \\
\hline
\end{tabular}




\section{Table 6}

Sensitivity analysis of end-point impacts considering the influence of a single expert.

\begin{tabular}{|c|c|c|c|c|c|c|c|c|}
\hline & $\begin{array}{l}\text { Without } \\
\text { Expert1 }\end{array}$ & $\begin{array}{l}\text { Without } \\
\text { Expert2 }\end{array}$ & $\begin{array}{l}\text { Without } \\
\text { Expert3 }\end{array}$ & $\begin{array}{l}\text { Without } \\
\text { Expert4 }\end{array}$ & $\begin{array}{l}\text { Without } \\
\text { Expert5 }\end{array}$ & $\begin{array}{l}\text { Without } \\
\text { Expert6 }\end{array}$ & $\begin{array}{l}\text { Without } \\
\text { Expert7 }\end{array}$ & $\begin{array}{l}\text { Original } \\
\text { Overall }\end{array}$ \\
\hline Minimum & & & & & & & & \\
\hline (VIP analysis) & 0.20 & 0.20 & 0.35 & 0.20 & 0.20 & 0.20 & 0.20 & 0.20 \\
\hline Maximum & & & & & & & & \\
\hline (VIP analysis) & 0.80 & 0.80 & 0.80 & 0.80 & 0.60 & 0.80 & 0.80 & 0.80 \\
\hline Mean & 0.43 & 0.46 & 0.49 & 0.47 & 0.39 & 0.46 & 0.46 & 0.45 \\
\hline Std Dev & 0.07 & 0.07 & 0.06 & 0.07 & 0.04 & 0.07 & 0.07 & 0.06 \\
\hline $\begin{array}{l}\% \text { of cases with } \\
\mathrm{I}(\text { manual })- \\
\mathrm{I}(\text { mechanical })<0\end{array}$ & 0 & 0 & 0 & 0 & 0 & 0 & 0 & 0 \\
\hline
\end{tabular}

\subsubsection{Sensitivity analysis}

Table 6 presents the results of the sensitivity analysis of end-point impacts of manual and mechanical harvesting systems. The mechanical system always has lower impacts than the manual system, regardless of which expert is removed. The mechanical system possesses the smallest advantages in the range of $[0.20,0.35]$, and the largest advantages of $[0.60,0.80]$. No particular expert has a large influence on the overall conclusions.

When compared to the LCA results at the mid-point, the results at the end-point are more robust (concerning decision maker preferences) and favor the mechanical system, which appears to contradict the conclusions that can be drawn based on mid-point indicators. It is even possible to note that removing expert 3 benefits the manual system and removing expert 5 benefits the mechanical system when considering the mid-point analysis. However, in considering the end-point analysis, the contrary occurs (without calling into question the robust conclusion of the mechanical system's superiority in the latter case).

The results of this article are consistent with the general perception that aggregating LCA results at the end-point may ease the process of resolving trade-offs across indicators for decision makers (Bare et al., 2000); however, it is also important to bear in mind the higher uncertainties of end-point impacts compared to the mid-point. The apparent differences we find in this study when performing multi-criteria decision analysis using mid-point and end-point indicators suggest including both mid-point and end-point indicators in LCA is beneficial for informing decision-making. However, more research is needed to understand how mid-point 
and end-point can be included in a framework in a consistent manner, and how results at two levels can be integrated to support decision-making.

\subsection{Social impacts}

\subsubsection{Comparing social impacts by social themes}

Quantification of the social impacts of the manual and mechanical systems by social themes is presented in Table 7 ( 0 is better and 1 is worse). A summary of the qualitative comparison of social impacts of manual and mechanical harvesting can be found in Table 3 in Supplementary Material. Mechanical harvesting is better according to most indicators: Health and safety, Fair salary, Delocalization and migration, Public commitment to sustainability issues, Safe and healthy living conditions and Equal opportunity and discrimination. On the other hand, manual harvesting is better according to the indicators of Local employment and Access to material resources (for details, see Du et al., 2018).

\section{Table 7}

Quantitative S-LCA results of the manual and mechanical systems by social themes

\begin{tabular}{lcc}
\hline Subcategory & Manual harvesting & Mechanical harvesting \\
\hline Health and safety & 1 & 0 \\
Local employment & 0 & 1 \\
Fair salary & 1 & 0 \\
Access to material resources & 0 & 1 \\
$\begin{array}{l}\text { Delocalization and migration } \\
\text { Public commitment to }\end{array}$ & 1 & 0 \\
$\begin{array}{l}\text { sustainability issues } \\
\text { Safe and healthy living }\end{array}$ & 1 & 0 \\
conditions & 1 & 0 \\
$\begin{array}{l}\text { Equal opportunity and } \\
\text { discrimination }\end{array}$ & 1 & 0 \\
\hline
\end{tabular}

Table 8 presents the weights provided by experts on eight social indicators (divided by 100 in the final analysis). The weight vectors of the weights assigned to decision makers are simulated for 100,000 iterations and the simulated results for overall social impacts are presented in Fig. 4. The differences between the social impacts of the manual and mechanical systems (subtracting mechanical from manual) are always positive, suggesting that the mechanical system clearly has better overall impacts than the manual system. The advantages of the mechanical system are quite large, falling in the range of $[0.40,0.80]$. 


\section{Table 8}

Survey results of weights of relevant social subcategories

\begin{tabular}{lccccccc}
\hline Social issues & Expert 1 & Expert 2 & Expert 3 & Expert 4 & Expert 5 & Expert 6 & Expert 7 \\
\hline Health and safety & 15 & 20 & 20 & 14.5 & 30 & 25 & 16 \\
$\begin{array}{l}\text { Local employment } \\
\text { Fair salary }\end{array}$ & 5 & 20 & 20 & 13.5 & 5 & 22.5 & 16 \\
$\begin{array}{l}\text { Access to material } \\
\text { resources }\end{array}$ & 25 & 20 & 20 & 10 & 20 & 17.5 & 14 \\
$\begin{array}{l}\text { Delocalization and } \\
\text { migration }\end{array}$ & 5 & 5 & 10 & 10 & 5 & 2.5 & 8 \\
$\begin{array}{l}\text { Public commitment of } \\
\text { sustainability issues }\end{array}$ & 25 & 10 & 0 & 10 & 0 & 12.5 & 12 \\
$\begin{array}{l}\text { Safe and healthy living } \\
\text { conditions }\end{array}$ & 5 & 10 & 0 & 12 & 25 & 7.5 & 10 \\
$\begin{array}{l}\text { Equal opportunity and } \\
\text { discrimination }\end{array}$ & 10 & 5 & 20 & 15 & 10 & 7.5 & 16 \\
\hline
\end{tabular}

\subsubsection{Sensitivity analysis}

Table 9 summarizes the results of the sensitivity analysis of the social impacts of the manual and mechanical systems by removing one expert at a time. The conclusions are consistently and overwhelmingly in favor of the mechanical system regardless of which expert is removed. The margins of advantage in all the cases are very close to each other, with differences of less than 0.1 .

\section{Table 9}

Sensitivity analysis of social impacts considering the influence of a single expert.

\begin{tabular}{|c|c|c|c|c|c|c|c|c|}
\hline & $\begin{array}{l}\text { Without } \\
\text { Expert1 }\end{array}$ & $\begin{array}{l}\text { Without } \\
\text { Expert2 }\end{array}$ & $\begin{array}{l}\text { Without } \\
\text { Expert3 }\end{array}$ & $\begin{array}{l}\text { Without } \\
\text { Expert4 }\end{array}$ & $\begin{array}{l}\text { Without } \\
\text { Expert5 }\end{array}$ & $\begin{array}{l}\text { Without } \\
\text { Expert6 }\end{array}$ & $\begin{array}{l}\text { Without } \\
\text { Expert7 }\end{array}$ & $\begin{array}{l}\text { Original } \\
\text { Overall }\end{array}$ \\
\hline $\begin{array}{l}\text { Minimum } \\
\text { (VIP analysis) }\end{array}$ & 0.40 & 0.40 & 0.50 & 0.40 & 0.40 & 0.40 & 0.40 & 0.40 \\
\hline $\begin{array}{l}\text { Maximum } \\
\text { (VIP analysis) }\end{array}$ & 0.80 & 0.80 & 0.80 & 0.80 & 0.80 & 0.80 & 0.80 & 0.80 \\
\hline Mean & 0.541 & 0.591 & 0.608 & 0.587 & 0.541 & 0.591 & 0.588 & 0.578 \\
\hline $\begin{array}{l}\text { Std Dev } \\
\% \text { of cases with } \\
\text { I(manual) - }\end{array}$ & 0.0466 & 0.0579 & 0.0516 & 0.0590 & 0.0464 & 0.0582 & 0.0587 & 0.0517 \\
\hline $\mathrm{I}($ mechanical $)<0$ & 0 & 0 & 0 & 0 & 0 & 0 & 0 & 0 \\
\hline
\end{tabular}

\section{Conclusions}

This article presented a novel MCDA model in the LCIA phase to support group decision making, based on comparative LCA and S-LCA results, applied to a study of sugarcane production with manual and mechanical harvesting in Brazil. It followed a different methodology from the recent work concurrently carried out by Cardoso et al (2018), wherein a different set of indicators (including technical and economic ones) and a different MCDA 
approach were used, thus rendering the results not comparable. Cardoso et al. (2018) obtained three different MCDA results by using three different vectors of weights (used as examples) and considering all indicators simultaneously, whereas the present study analyzed the environmental (both mid-point and end-point) and social dimensions separately and obtained weights representing the views of a sample of decision-makers.

This article utilized value choices of specific decision-makers, but it adopted stochastic weights to explore all the possible combinations of the weights they provided. Sensitivity analysis is conducted to test the robustness of the results, which consistently show that mechanical harvesting has lower environmental impacts at the end-point and lower social impacts. However, the results of the environmental impacts at the mid-point were less robust and clear: manual harvesting appears more likely (67\% of the convex combinations of the weights) to have lower impacts than mechanical harvesting, but the advantage of mechanical harvesting over manual harvesting can be greater than the reverse (almost twice as large). These findings suggest that mechanical harvesting of sugarcane should be accelerated, especially in areas with lower mechanization levels such as Brazil's North-Northeast since it can reduce environmental impacts and also generate positive social impacts by increasing average income, improving social equality and fair salary. Despite the methodological differences between this study and Cardoso et al (2018), the conclusions of both are well aligned.

At the methodological level, this work emphasizes the relevance of providing to decision-makers both mid-point and end-point when comparing the environmental impacts of different product life cycles. It also shows a possible way of applying MCDA when multiple decision makers indicate different weighting vectors. The MCDA approach developed in this article can be adopted in future comparative LCA and/or S-LCA studies to support decisionmaking by utilizing expert or stakeholder preference information while improving comparative robustness.

\section{Acknowledgments}

We thank the reviewers for their helpful comments that contributed to improving this article. This work was supported by the Portuguese Science and Technology Foundation (FCT) (grant number SFRH/BD/51948/2012; project SABIOS with project identifier PTDC/AAGMAA/6234/2014 and POCI-01-0145-FEDER-016765). This work was developed under the framework of the Energy for Sustainability Initiative of the University of Coimbra. 


\section{References}

Arbex, M.A., Martins, L.C., de Oliveira, R.C., Pereira, L.A.A., Arbex, F.F., Cancado, J.E.D., Saldiva, P.H.N., Braga, A.L.F., 2007. Air pollution from biomass burning and asthma hospital admissions in a sugar cane plantation area in Brazil. J. Epidemiol. Community Heal. 61, 395-400. http://doi.org/10.1136/jech.2005.044743

Bare, J.C., Hofstetter, P., Pennington, D.W., Udo de Haes, H.A., 2000. Midpoints versus endpoints: the sacrifices and benefits. Int. J. Life Cycle Assess. http://doi.org/ 10.1007/BF02978665

Bonomi, A., Cavalett, O., Pereira da Cunha, M., Lima, M., 2016. Virtual biorefinery: an optimization strategy for renewable carbon valorization. p285. Springer International Publishing.

Butler, J., Jia, J., Dyer, J., 1997. Simulation techniques for the sensitivity analysis of multicriteria decision models. Eur. J. Oper. Res. 103, 531-546.

Cançado, J.E.D., Saldiva, P.H.N., Pereira, L.A.A., Lara, L.B.L.S., Artaxo, P., Martinelli, L.A., Arbex, M.A., Zanobetti, A., Braga, A.L.F., 2006. The Impact of Sugar Cane-Burning Emissions on the Respiratory System of Children and the Elderly. Environ. Health Perspect. 114, 725-729. http://doi.org/10.1289/ehp.8485

Cardoso, T.F., Watanabe, M. D., Souza, A., Chagas, M. F., Cavalett, O. et al., 2018. Economic, environmental, and social impacts of different sugarcane production systems. Biofuels, Bioproducts and Biorefining. 12(1), 68-82.

Cavalett, O., Chagas, M.F., Seabra, J.E.A, Bonomi, A., 2013. Comparative LCA of ethanol versus gasoline in Brazil using different LCIA methods. Int. J. Life Cycle Assess. 18:647658.

Chagas, M.F., Bordonal, R., Cavalett, O., Carvalho, J.L.N., Bonomi, A., Jr., N.L.S., 2016. Environmental and economic impacts of different sugarcane production systems in the ethanol biorefinery. Biofuels, Bioprod. Biorefining 10, 89-106. http://doi.org/10.1002/bbb

Czitrom, V., 1999. One-factor-at-a-time versus designed experiments. The American Statistician 53(2), 126-131.

Dias, L. C., Clímaco, J. N., 2000. Additive Aggregation with Variable Interdependent Parameters: the VIP Analysis Software. Journal of the Operational Research Society 51, 1070-1082.

Dias, L.C., Domingues, A.R., 2014. On multi-criteria sustainability assessment: Spider-gram surface and dependence biases. Applied Energy 113, 159-163.

Dias, L.C., Passeira, C., Malça, J., Freire, F., 2016. Integrating life-cycle assessment and multicriteria decision analysis to compare alternative biodiesel chains. Ann. Oper. Res. 
http://doi.org/10.1007/s10479-016-2329-7

Doderer, C.C.C. Von, Kleynhans, T.., 2014. Determining the most sustainable lignocellulosic bioenergy system following a case study approach. Biomass and Bioenergy 70, 273-286. http://doi.org/10.1016/j.biombioe.2014.08.014

Domingues, A.R., Marques, P., Garcia, R., Freire, F., Dias, L.C., 2015. Applying Multi-Criteria Decision Analysis to the Life-Cycle Assessment of vehicles. J. Clean. Prod. 107, 749-759. http://doi.org/10.1016/j.jclepro.2015.05.086

Du, C., Freire, F., Dias, L.C., 2014. Overview of social life-cycle assessment. 2014 avniR Conference Proceedings - Life Cycle in Practice, Lille, France.

Du, C., Kulay, L., Cavalett, O., Dias, L., Freire, F., 2017. Life cycle assessment addressing health effects of particulate matter of mechanical versus manual sugarcane harvesting in Brazil. Int. J. Life Cycle Assess. http://doi.org/10.1007/s11367-017-1334-7

Du, C., Ugaya, C., Freire, F., Dias, L., Clift, R., 2018. Enriching the results of screening S-LCA using content analysis: a case study of sugarcane in Brazil. Int. J. Life Cycle Assess. http://doi.org/10.1007/s11367-018-1490-4

Duarte, C.G., Gaudreau, K., Gibson, R.B., Malheiros, T.F., 2013. Sustainability assessment of sugarcane-ethanol production in Brazil : A case study of a sugarcane mill in São Paulo state. Ecol. Indic. 30, 119-129. http://doi.org/10.1016/j.ecolind.2013.02.011

Dyer, J., Sarin, R., 1979. Group preference aggregation rules based on strength of preference. Management Science 25(9), 822-832.

Galdos, M., Cavalett, O., Seabra, J.E.A., Nogueira, L.A.H., Bonomi, A., 2013. Trends in global warming and human health impacts related to Brazilian sugarcane ethanol production considering black carbon emissions. Appl. Energy 104, 576-582. http://doi.org/10.1016/j.apenergy.2012.11.002

Goedkoop, M., Heijungs, R., Huijbregts, M., Schryver, A., Struijs, J. et al., 2013. ReCiPe 2008. A LCIA method which comprises harmonised category indicators at the midpoint and the endpoint level. http://www.leidenuniv.nl/cml/ssp/publications/recipe_characterisation.pdf (accessed 11 March 2018).

Guinée, J., 2002. Handbook on life cycle assessment operational guide to the ISO standards. http://doi.org/10.1007/BF02978897

Guinée, J., Heijungs, R., Huppes, G., Zamagni, A., Masoni, P. et al., 2011. Life cycle assessment: past, present, and future. Environ Sci Technol 45, 90-96.

Huppes, G., van Oers, L., 2011. Background review of existing weighting approaches in Life Cycle Impact Assessment (LCIA). http://www.avnir.org/documentation/e_book/BackgroundReviewExistingWeightingAppro 
chesInLCIA.pdf (accessed 11 March 2018).

ISO, 2006a. ISO 14040. Environmental Management - Life Cycle Assessment - Principles and Framework. International Organization for Standardization.

ISO, 2006b. ISO 14044. Environmental Management - Life Cycle Assessment - Requirements and Guidelines. International Organization of Standardization.

Keeney, R., Kirkwood, C., 1975. Group decision making using cardinal social welfare functions. Management Science 22(4), 430-437.

Keeney, R., Raiffa, H., 1993. Decisions with multiple objectives-preferences and value tradeoffs. Cambridge University Press, Cambridge \& New York

Lipuscek, I., Bohanec, M., Oblak, L., Stirn, L.Z., 2010. A multi-criteria decision-making model for classifying wood products with respect to their impact on environment. Int. J. Life Cycle Assess. 15, 359-367. http://doi.org/10.1007/s11367-010-0157-6

Luo, L., Voet, E., Huppes, G., 2009. Life cycle assessment and life cycle costing of bioethanol from sugarcane in Brazil. Renew. Sust. Ener. Rev.. 13:1613-1619.

Macedo, I.C., Seabra, J.E. a, Silva, J.E. a R., 2008. Green house gases emissions in the production and use of ethanol from sugarcane in Brazil: The 2005/2006 averages and a prediction for 2020. Biomass and Bioenergy 32, 582-595. http://doi.org/10.1016/j.biombioe.2007.12.006

Miettinen, P., Hamalainen, R.P., 1997. How to benefit from decision analysis in environmental life cycle assessment (LCA). Eur. J. Oper. Res. 279-294.

Myllyviita, T., Holma, A., Antikainen, R., Lähtinen, K., Leskinen, P., 2012. Assessing environmental impacts of biomass production chains - application of life cycle assessment (LCA) and multi-criteria decision analysis (MCDA). J. Clean. Prod. 29-30, 238-245. http://doi.org/10.1016/j.jclepro.2012.01.019

Myllyviita, T., Leskinen, P., Seppala, J., 2014. Impact of normalization, elicitation technique and background information on panel weighting results in life cycle assessment. Int J Life Cycle Assess 19, 377-386.

Narayanan, D., Zhang, Y., Mannan, M., 2007. Engineering for sustainable development (ESD) in bio-diesel production. Process Saf. Environ. Prot. 85, 349-359. http://doi.org/10.1205/psep07016

Norris, G.A., 2001. The requirement for. congruence in normalization. Int. J. Life Cycle Assess. 6, 85. http://doi.org/ 10.1007/BF02977843

Pastare, L., Romagnoli, F., Lauka, D., Dzene, I., Kuznecova, T., 2014. Sustainable use of macro-algae for biogas production in Latvian conditions: a preliminary study through an integrated MCA and LCA approach. Environ. Clim. Technol. 13, 44-56. 
http://doi.org/10.2478/rtuect-2014-0006

Pizzol, M., Laurent, A., Sala, S., Weidema, B., Verones, F., Koffler, C., 2017. Normalisation and weighting in life cycle assessment: quo vadis? Int. J. Life Cycle Assess. 22, 853-866. http://doi.org/10.1007/s11367-016-1199-1

Prado-Lopez, V., Seager, T.P., Chester, M., Laurin, L., Bernardo, M., Tylock, S., 2014. Stochastic multi-attribute analysis (SMAA) as an interpretation method for comparative life-cycle assessment (LCA). Int. J. Life Cycle Assess. 19, 405-416. http://doi.org/10.1007/s11367-013-0641-x

Rogers, K., Seager, T.P., 2009. Environmental decision-making using Life Cycle Impact Assessment and Stochastic Multiattribute Decision Analysis: a case study on alternative transportation fuels. Environ. Sci. Technol. 43, 1718-1723.

Saaty, T.L., 2008. Decision making with the analytic hierarchy process. International journal of services sciences, 1(1), 83-98.

Sarabando, P., Dias, L.C., Vetschera, R., 2017. Group decision making with incomplete information: a dominance and quasi-optimality volume-based approach using Monte-Carlo simulation. International Transactions in Operational Research (forthcoming).

Seabra, J.E.A, Macedo, I.C., Chum, H.L., Faroni, C.E., Sarto, C.A., 2011. Life cycle assessment of Brazilian sugarcane products: GHG emissions and energy use. Biofuels, Bioprod., Bioref. 5:519-532.

Souza, A., Watanabe, M.D.B., Cavalett, O., Ugaya, C.M.L., Bonomi, A., 2016. Social life cycle assessment of first and second-generation ethanol production technologies in Brazil. Int. J. Life Cycle Assess. http://doi.org/10.1007/s11367-016-1112-y

UNEP/SETAC, 2009. Guidelines for Social Life Cycle Assessment. http://www.unep.fr/shared/publications/pdf/dtix1164xpa-guidelines_slca.pdf (accessed 5 October 2018).

UNICA, 2010. UNICA Sustainability Report 2010. http://www.unica.com.br/sustainabilityreporting/ (accessed 5 October 2018).

UNICA, 2017. UNICADATA project. http://www.unicadata.com.br/ (accessed 11 March 2018).

Viana, K.R.O., Perez, R., 2013. Survey of sugarcane industry in Minas Gerais , Brazil : Focus on sustainability. Biomass and Bioenergy 58, 149-157. http://doi.org/10.1016/j.biombioe.2013.08.006 